\title{
Time resolved spectroscopic studies on some nanophosphors
}

\author{
HARISH CHANDER and SANTA CHAWLA* \\ Electronic Materials Division, National Physical Laboratory, Dr K S Krishnan Road, \\ New Delhi 110 012, India
}

\begin{abstract}
Time resolved spectroscopy is an important tool for studying photophysical processes in phosphors. Present work investigates the steady state and time resolved photoluminescence (PL) spectroscopic characteristics of $\mathrm{ZnS}, \mathrm{ZnO}$ and $(\mathrm{Zn}, \mathrm{Mg}) \mathrm{O}$ nanophosphors both in powder as well as thin film form. Photoluminescence (PL) of ZnS nanophosphors typically exhibit a purple/blue emission peak termed as self activated (SA) luminescence and emission at different wavelengths arising due to dopant impurities e.g. green emission for $\mathrm{ZnS}: \mathrm{Cu}$, orange emission for $\mathrm{ZnS}: \mathrm{Mn}$ and red emission for $\mathrm{ZnS}: \mathrm{Eu}$. The lifetimes obtained from decay curves range from $\mathrm{ns}$ to $\mathrm{ms}$ level and suggest the radiative recombination path involving donor-acceptor pair recombination or internal electronic transitions of the impurity atom. A series of $\mathrm{ZnMgO}$ nanophosphor thin films with varied $\mathrm{Zn}$ : Mg ratios were prepared by chemical bath deposition. Photoluminescence (PL) excitation and emission spectra exhibit variations with changing $\mathrm{Mg}$ ratio. Luminescence lifetime as short as $10^{-10} \mathrm{~s}$ was observed for ZnO and ZnMgO (100:10) nanophosphors. With increasing Mg ratio, PL decay shifts into microsecond range. $\mathrm{ZnO}$ and $\mathrm{ZnMgO}$ alloys up to $50 \% \mathrm{Mg}$ were prepared as powder by solid state mixing and sintering at high temperature in reducing atmosphere. Time resolved decay of PL indicated lifetime in the microsecond time scale. The novelty of the work lies in clear experimental evidence of dopants $(\mathrm{Cu}, \mathrm{Mn}, \mathrm{Eu}$ and $\mathrm{Mg})$ in the decay process and luminescence life times in II-VI semiconductor nanocrystals of ZnS and ZnO. For ZnS, blue self activated luminescence decays faster than $\mathrm{Cu}$ and $\mathrm{Mn}$ related emission. For undoped $\mathrm{ZnO}$ nanocrystals, PL decay is in the nanosecond range whereas with $\mathrm{Mg}$ doping the decay becomes much slower in the microsecond range.
\end{abstract}

Keywords. Photoluminescence (PL); time resolved decay; lifetime; nanophosphor.

\section{Introduction}

Time resolved spectroscopy is an important tool for studying energy and charge transfer processes, coupling of electronic and vibrational degrees of freedom, vibrational and conformational relaxation, isomerization, etc. The decay characteristics of phosphors could suggest the process of excitation and return to ground state and their time scale. It employs excitation by very short pulses of radiation like flash lamps, lasers etc, which can be spectrally tuned to the electronic transitions of the material to be studied. Doped nanophosphors have been the topic of intense research for their colour tunability and better luminescence efficiency leading to a wide variety of applications as light emitters in UV and visible (Bhargava et al 1994; Chander 2005). ZnS has been the workhorse as conventional phosphor whose application range included photoluminescence (PL), electroluminescence (EL) and cathodoluminescence (CL) devices. In the present study, $\mathrm{ZnS}$ nanophosphors have been doped with $\mathrm{Cu}, \mathrm{Mn}$ and rare earth ion, $\mathrm{Eu}$ and the difference in photoluminescence and their decay characteristics due to dopant ion in

\footnotetext{
*Author for correspondence (santa@mail.nplindia.ernet.in)
}

the same nanophosphor has been investigated. $\mathrm{ZnO}$ and its ternary alloy, $\mathrm{ZnMgO}$, offer an excellent wide bandgap semiconducting material system with potential in applications related to quantum well and photonic devices in UV and visible. Earlier work on $\mathrm{Zn}_{x} \mathrm{Mg}_{1-x} \mathrm{O}$ thin film includes study of electrical and optical property (Kim et al 2006), bandgap variation with $\mathrm{Mg}$ content (Matsuhara et al 2003; Ogawa and Fujihara 2005), room temperature UV emission (Jin et al 2004). An understanding of the charge carrier dynamics in nanocrystalline semiconductor thin films is of much importance for their applications in PL and EL display devices.

Characterization of luminescence emission from a phosphor needs study of a few parameters like excitation and emission energy, luminescence efficiency, polarization and decay time. Excitation and emission spectra have been used routinely to identify luminescence characteristics of any phosphor. But time resolved spectroscopy of the luminescence decay provides an opportunity to probe into the temporal dynamics and the kinetics of the photophysical processes of the phosphor in the time domain. Towards this goal, the present study encompasses steady state PL and time resolved decay measurement of undoped and doped $\mathrm{ZnS}$ nanophosphors, $\mathrm{ZnO}$ and $\mathrm{ZnMgO}$ nanocrystalline thin films and powders. 


\section{Experimental}

\subsection{Synthesis and film deposition}

Undoped and $\mathrm{Cu}$ doped $\mathrm{ZnS}$ nanophosphor in thin film form was prepared by a wet chemical method using zinc acetate dihydrate, thiourea, urea, triethanolamine and copper (II) acetate monohydrate. $\mathrm{ZnS}: \mathrm{Eu}$ nanophosphor was prepared by the same method by using europium nitrate solution instead of copper (II) acetate monohydrate. The reaction was carried out at $80^{\circ} \mathrm{C}$ under continuous stirring. $\mathrm{ZnS}: \mathrm{Mn}$ was also prepared by wet chemical method (Karar et al 2004).

For wet chemical synthesis of $\mathrm{ZnMgO}$ with varied concentrations of $\mathrm{Mg}$, precursor solutions of zinc acetate, magnesium chloride and triethanolamine were used. For deposition of film, precleaned glass slides were introduced vertically and chemical bath deposition was done at $80^{\circ} \mathrm{C}$ using a constant heating oil bath for times varying from 10 to $120 \mathrm{~min}$. After the deposition, the glass slides were thoroughly cleaned with deionized water and dried in an oven at $50-80^{\circ} \mathrm{C}$. $\mathrm{Zn}: \mathrm{Mg}$ ratio was varied from $100: 0$ to $100: 30$ and good solubility was found in that range.

The typical solid state reaction method for synthesis of $\mathrm{ZnMgO}$ composites was as follows. Zinc oxide ( $1 \mathrm{M})$ was ground for $5 \mathrm{~min}$ and magnesium carbonate $(0 \cdot 2 \mathrm{M})$ was added to zinc oxide. After the mixture was ground for 20-30 min, the sample was packed in an alumina boat. Prior to use it was properly cleaned by $\mathrm{HCl}$ to make it free from impurities present in the boat. The packed sample was fired at $\sim 1200^{\circ} \mathrm{C}$ for $3-5 \mathrm{~h}$, using tube furnace with ammonia and nitrogen gas atmosphere.

\subsection{Characterization}

Structural characterization of the synthesized nanophosphors was done by XRD using Brucker-AXS D8 advance diffractometer with $\mathrm{CuK} \alpha$ radiation. For nanophosphor thin films, glancing angle $\left(1^{\circ}\right) \mathrm{XRD}$ profile was taken due to thinness of the deposited films. Morphology was studied with scanning electron microscope. Photoluminescence and time resolved decay of PL were measured in Perkin Elmer LS55 Fluorescence spectrometer and Edinburgh Instruments FLSP920 combined steady state Fluorescence and Phosphorescence lifetime spectrometer, respectively.

\section{Results and discussion}

\subsection{Structure}

XRD patterns of $\mathrm{ZnS}: \mathrm{Mn}$ and $\mathrm{ZnMgO}$ nanophosphor are shown in figures 1(a) and (b), respectively. Particle size of the synthesized $\mathrm{ZnS}$, estimated from XRD, SEM and TEM, was in the range $2-4 \mathrm{~nm}$. XRD pattern of $\mathrm{ZnMgO}$ films on glass substrate exhibit hexagonal wurtzite structure of $\mathrm{ZnO}$ (JCPDS card no 36-1451). The films show good crystalline structure (Chawla et al 2006). The particle size estimated from Scherrer formula was approximately $50 \mathrm{~nm}$. The films hence essentially comprised of nano-
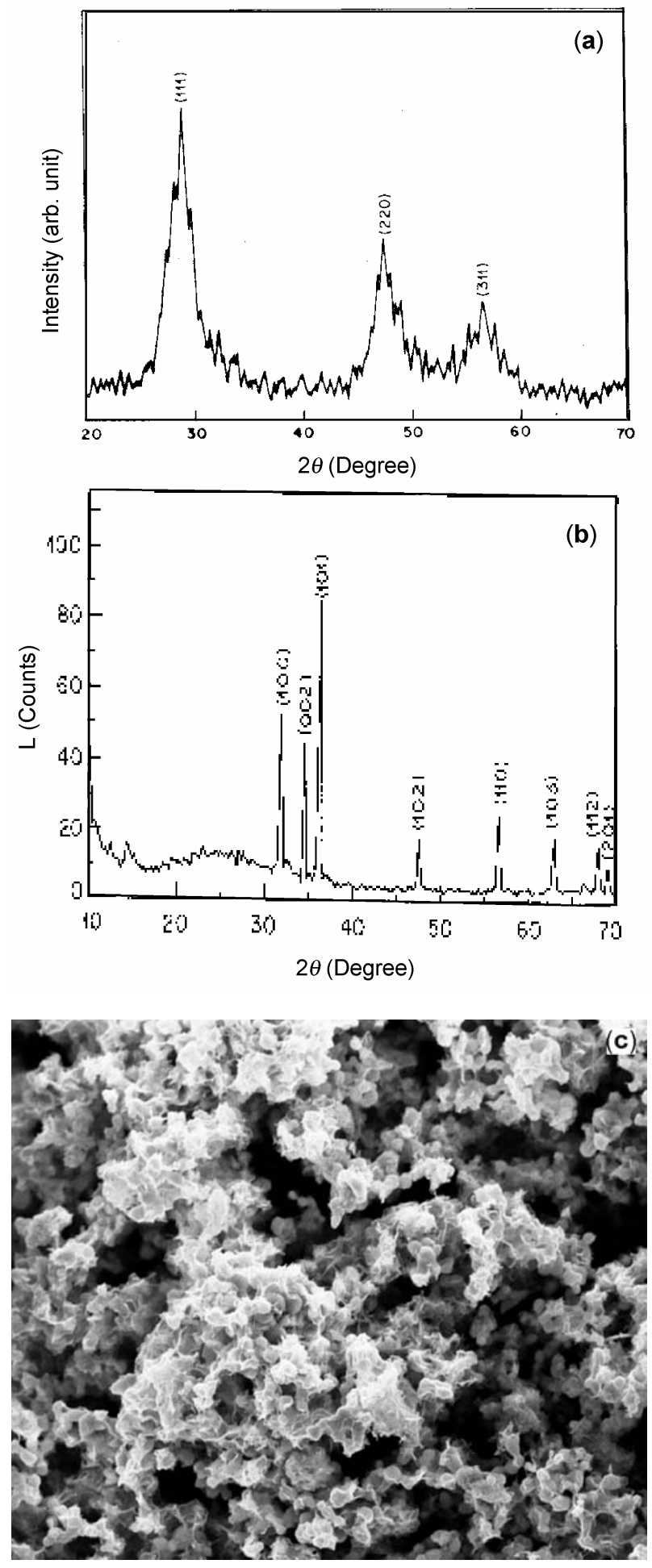

Figure 1. XRD pattern of (a) $\mathrm{ZnS}: \mathrm{Mn}$, (b) $\mathrm{ZnMgO}$ and (c) SEM micrograph of $\mathrm{ZnMgO}$ nanophosphor. 
phosphor of $\mathrm{ZnMgO}$ with varied $\mathrm{Mg}$ ratio from 0 to $30 \%$ of $\mathrm{Zn}$ content. SEM micrograph of $\mathrm{ZnMgO}$ nanophosphor films indicates uniform distribution of particles. For the
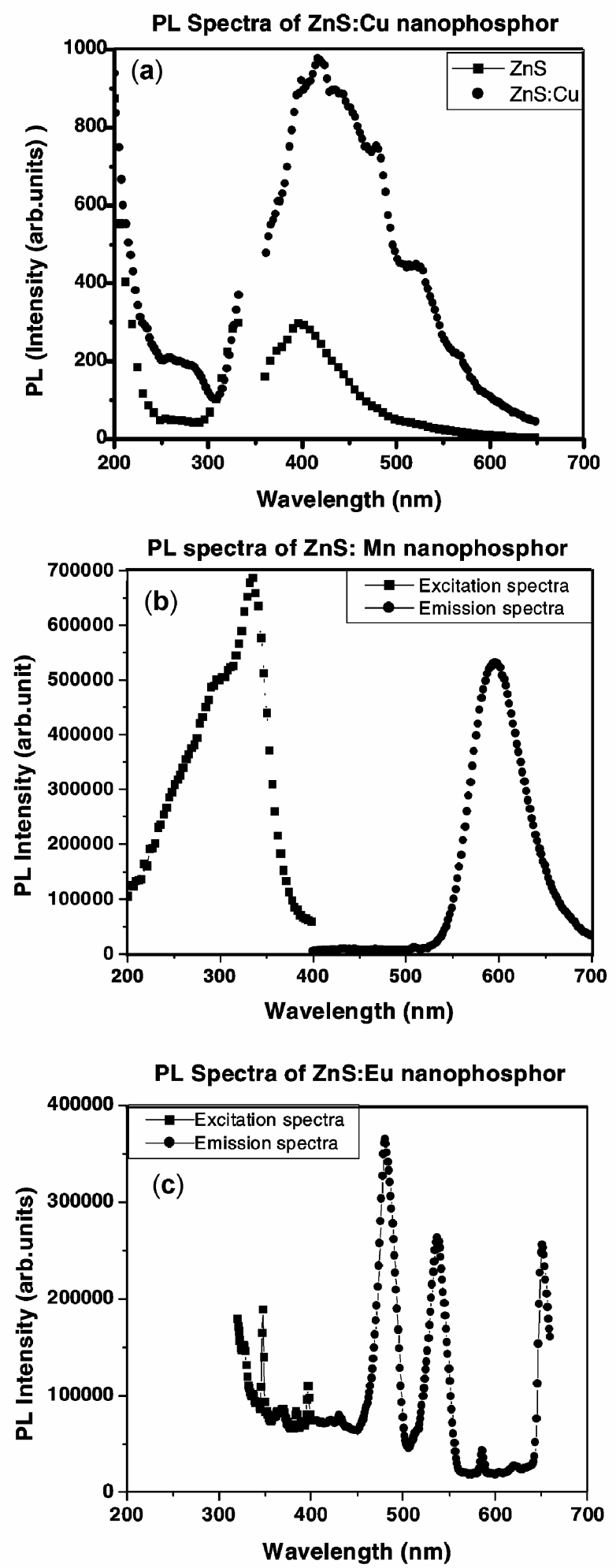

Figure 2. PL excitation and emission spectra of (a) undoped and $\mathrm{Cu}$ doped $\mathrm{ZnS}$, (b) $\mathrm{ZnS}: \mathrm{Mn}$ and (c) $\mathrm{ZnS}: \mathrm{Eu}$ nanophosphor. samples prepared at $\sim 1200^{\circ} \mathrm{C}, \mathrm{ZnO}$ and $\mathrm{MgO}$ phases were clearly identified by the presence of wurtzite $\mathrm{ZnO}$ and cubic diffraction peaks (Chander et al 2006). This fact indicated that the synthesized product was not a single phase but a composite. The average particle size of the $\mathrm{ZnMgO}$ powder sample was estimated to be $\sim 35 \mathrm{~nm}$. The SEM results (figure 1c) were consistent with XRD results. For $\mathrm{ZnS}$ nanophosphors, TEM was done and particle size estimated conform to XRD results.

\subsection{Photoluminescence}

PL excitation and emission spectra of undoped $\mathrm{ZnS}$ and $\mathrm{ZnS}: \mathrm{Cu}, \mathrm{ZnS}: \mathrm{Mn}$ and $\mathrm{ZnS}: \mathrm{Eu}$ are shown in figures 2(a), (b) and (c), respectively. Undoped $\mathrm{ZnS}$ nanophosphor showed two peaks at $390 \mathrm{~nm}$ and $430 \mathrm{~nm} . \mathrm{ZnS}$ : $\mathrm{Cu}$ nanophosphors showed three PL emission peaks at 420,480 and $525 \mathrm{~nm} . \mathrm{ZnS}$ : Mn showed a prominent orange peak at $595 \mathrm{~nm}$ and a subdued $430 \mathrm{~nm}$ peak at $340 \mathrm{~nm}$ excitation. $\mathrm{ZnS}: \mathrm{Eu}$ on the other hand exhibited a small peak at $430 \mathrm{~nm}$
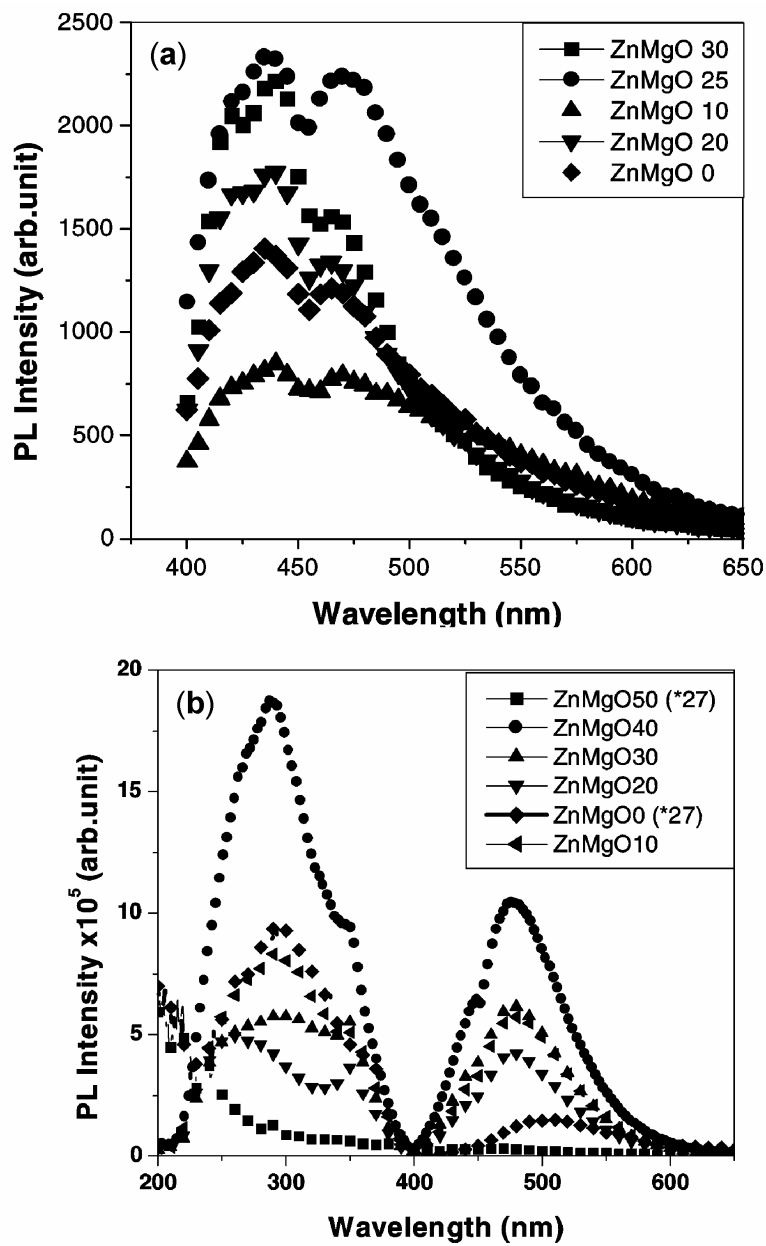

Figure 3. PL excitation and emission spectra of (a) $\mathrm{ZnMgO}$ nanophosphor thin films and (b) $\mathrm{ZnMgO}$ nanophosphor powder. 
Table 1. Peak emission wavelengths of $\mathrm{ZnS}$ nanophosphors.

\begin{tabular}{lcccc}
\hline Phosphor & Peak 1 (nm) & Peak 2 (nm) & Peak 3 (nm) & Peak 4 (nm) \\
\hline ZnS undoped & 430 & & & \\
ZnS : Cu & 420 & 480 & 525 & \\
ZnS : Mn & 430 & 595 & 538 & 651 \\
ZnS : Eu & 430 & 481 & 538 \\
\hline
\end{tabular}

Time resolved decay of $\mathrm{ZnMgO}$ nanophosphor

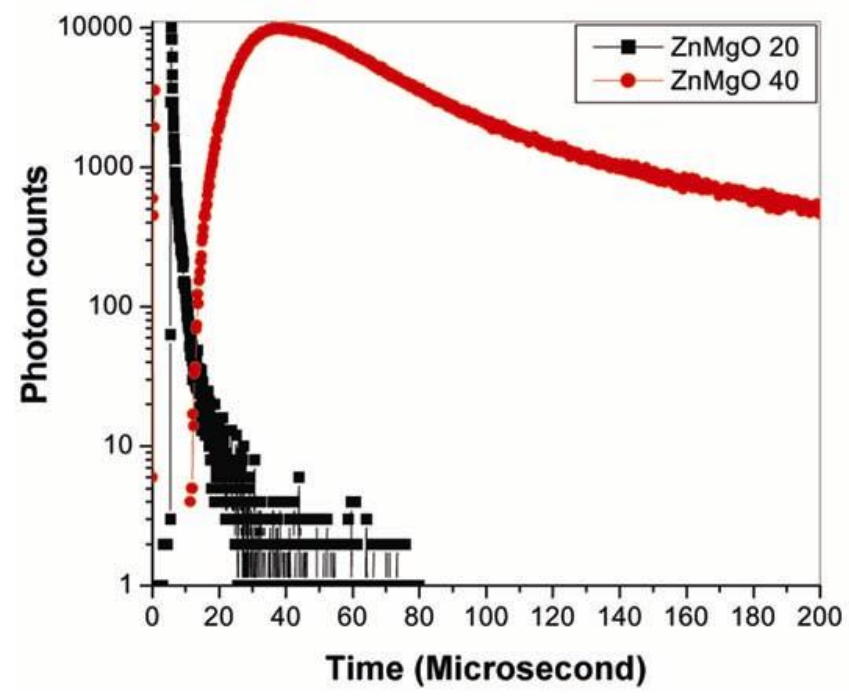

Figure 4. Time resolved luminescence decay of $\mathrm{ZnMgO}$ nanophosphor powders.

and sharp emission peaks characteristic of rare earth ions at 481, 538 and $651 \mathrm{~nm}$. All the ZnS samples showed excitation peaks around $200 \mathrm{~nm}$ and $340 \mathrm{~nm}$ for $420-430 \mathrm{~nm}$ emission. However, the orange emission in $\mathrm{ZnS}$ : Mn was maximum with $340 \mathrm{~nm}$ excitation. Peak emission wavelengths for all $\mathrm{ZnS}$ phosphors are listed in table 1. The $420-430 \mathrm{~nm}$ peak in $\mathrm{ZnS}$ has been classically termed as self activated luminescence and known to be due to recombination of carriers between sulphur vacancy $\left(V_{\mathrm{S}}\right)$ related donor and valence bands (Lee et al 2004). The $480 \mathrm{~nm}$ blue peak has been observed in both $\mathrm{ZnS}: \mathrm{Cu}$ and $\mathrm{ZnS}: \mathrm{Eu}$ and hence may arise due to native point defect e.g. recombination from conduction band to a zinc vacancy. The $525 \mathrm{~nm}$ peak in $\mathrm{ZnS}: \mathrm{Cu}$ is thought to be due to recombination between $V_{\mathrm{S}}$ and $\mathrm{Cu}$ related acceptor centre (Peng et al 2006).

Photoluminescence emission spectra of $\mathrm{ZnMgO}$ thin films under identical experimental parameters are shown in figure 3(a). The nanophosphor film with $\mathrm{Zn}: \mathrm{Mg}$ composition ratio, $100: 25$, exhibit maximum PL output under same excitation conditions. The PL spectra appear to be superposition of a few peaks and could be deconvoluted into four peaks approximately situated at $420 \mathrm{~nm}, 440 \mathrm{~nm}$, $462 \mathrm{~nm}$ and $500 \mathrm{~nm}$.
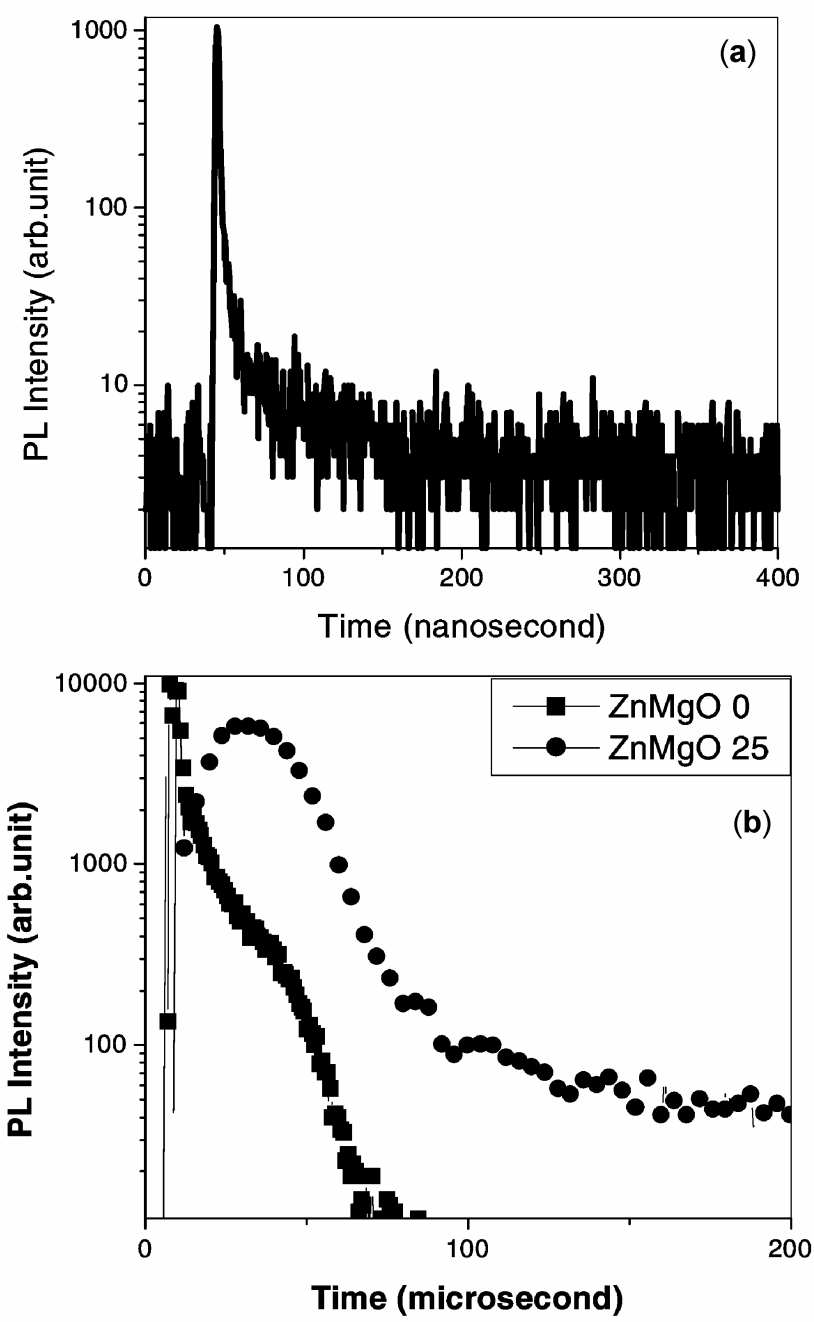

Figure 5. Time resolved decay of $\mathrm{ZnO}$ nanophosphor thin film with (a) nanosecond flash lamp and (b) microsecond flash lamp.

The photoluminescence excitation and emission spectra of $\mathrm{ZnMgO}$ nanophosphor powders (figure $3 \mathrm{~b}$ ) showed that the intensity was maximum for $\mathrm{ZnMgO}$ with $40 \mathrm{~mole} \%$ magnesium. The excitation spectra showed two prominent peaks, one around $290 \mathrm{~nm}$ and other around $350 \mathrm{~nm}$ whose position remained almost same for all the compositions. All the $\mathrm{ZnMgO}$ nanophosphor samples were then excited at $350 \mathrm{~nm}(3.5 \mathrm{eV})$. The emission spectra showed two peaks - one around $445 \mathrm{~nm}$ and a main peak at $508 \mathrm{~nm}$ in $\mathrm{ZnO}$ which blue shifts with increasing $\mathrm{Mg}$ content e.g. 
Table 2. Decay parameters of PL peaks of $\mathrm{ZnS}: \mathrm{Cu}$ nanophosphor.

\begin{tabular}{lcccrc}
\hline Nanophosphor & Emission peak $(\mathrm{nm})$ & $\tau_{1}(\mu \mathrm{s})$ & Relative $(\%)$ & $\tau_{2}(\mu \mathrm{s})$ & Relative $(\%)$ \\
\hline ZnS undoped & 420 & 0.69 & 61 & 5.12 & 39 \\
$\mathrm{ZnS}: \mathrm{Cu} 0.01 \mathrm{M}$ & 525 & 0.93 & 29 & 11.82 & 71 \\
$\mathrm{ZnS}: \mathrm{Cu} \mathrm{0.1 \textrm {M }}$ & 525 & 0.89 & 19 & 9.82 & 81 \\
\hline
\end{tabular}

Table 3. Decay parameters of PL peaks of $\mathrm{ZnS}: \mathrm{Mn}$ nanophosphor.

\begin{tabular}{lcccccc}
\hline $\begin{array}{l}\text { Emission } \\
\text { peak }(\mathrm{nm})\end{array}$ & $\tau_{1}(\mu \mathrm{s})$ & Relative $(\%)$ & $\tau_{2}(\mu \mathrm{s})$ & Relative $(\%)$ & $\begin{array}{c}\text { Long decay } \\
\text { component, } \tau(\mathrm{ms})\end{array}$ & $\begin{array}{c}\text { Long decay } \\
\text { component relative }(\%)\end{array}$ \\
\hline 430 & $2 \cdot 14$ & 7 & 14.65 & 93 & & 100 \\
595 & $2 \cdot 25$ & 3 & 27.63 & 97 & 1.6 & 100 \\
\hline
\end{tabular}

to $475 \mathrm{~nm}$ in $\mathrm{ZnMgO}$ (40 mole\%) and $468 \mathrm{~nm}$ in $\mathrm{ZnMgO}$ (50 mole\%).

\subsection{Time resolved luminescence spectroscopy}

Time resolved spectroscopy for luminescence lifetime measurement employed time correlated single photon counting technique. The sample was repetitively excited using a pulsed light source (ns flash lamp or $\mu \mathrm{s}$ Xe flash lamp). Scanning over many pulses, the resultant decay curve viewed on a semilogarithmic scale, indicate the exponential/multiexponential or complex kinetics. Data analysis involves numerical deconvolution and a direct fit to the kinetic model. The decay curves could be expressed mathematically as

$$
R(t)=A+\sum_{i=1}^{n} B_{i} e-t / \tau_{i}
$$

where $\tau_{i}$ represents characteristic lifetime and denotes the time taken to decay from the beginning of the decay to $37 \%$ of the original value, $B_{i}$ is a preexponential factor, which includes both instrumental and sample parameters. In a multiexponential decay, concentration ratio of individual components can be inferred from values of $B_{i}$. Two fitting routines are used, reconvolution fit and tail fit.

For extremely short exciting pulse, time resolved measurement showed a finite rising edge due to the exciting pulse. For precise estimation of short lifetimes the initial part of decay must be included in the analysis. Instrument response function plays an important role in the formation and initial decay part. In such case e.g. decay with nanosecond flash lamp (figure 5a), reconvolution fit routine has been employed after measuring the instrument response function in situ. Reconvolution fit routine allows one to fit over the rising edge of the data and eliminates both the noise and effects of the exciting pulse. Tail fit was applied for data which are fitted in a region with no further sample signal generation. Tail fit procedure eliminates the statistical noise from the raw data but cannot handle the region of sample excitation. Tail fit has been used for analysis of longer decay time (figures 4, $5 \mathrm{~b}, 6)$. In both the fit routines, iteration procedure was used for getting best set of decay parameters, $B_{i}$ and $\tau_{i}$. The 'goodness of fit' was ascertained by the reduced $\chi^{2}$ value which has the theoretical limit, 1 .

Time resolved decay of luminescence was recorded for $\mathrm{ZnS}: \mathrm{Cu}, \mathrm{ZnS}: \mathrm{Mn}$ and $\mathrm{ZnS}: \mathrm{Eu}$ nanophosphor at each peak emission wavelength (figure 6). The decay curves for $\mathrm{ZnS}: \mathrm{Mn}$ (figure 6b) clearly indicate that while the $430 \mathrm{~nm}$ component almost completely decays in $70 \mu \mathrm{s}$, the $595 \mathrm{~nm}$ component does so in $11 \mathrm{~ms}$. Decay measurement of $\mathrm{ZnS}: \mathrm{Mn}$ in $20 \mathrm{~ms}$ scale, gave a lifetime of the longer decaying component as $1.6 \mathrm{~ms}$ which matches well with reported value for cubic $\mathrm{ZnS}: \mathrm{Mn}$ and the long lifetime was supposed to be due to the spin and parity forbidden transition (Bhargava et al 1994; Peng et al 2006). The $\mu \mathrm{s}$ level decay times of $430 \mathrm{~nm}$ and $595 \mathrm{~nm}$ emissions may have the same origin in host $\mathrm{ZnS}$ lattice (Bol and Meijerink 1998). The results of luminescence lifetime measurements from fitting of single/multiexponential decay curves are listed in table 3 .

It can be seen from table 2 that decay of undoped $\mathrm{ZnS}$ nanophosphor is faster than $\mathrm{ZnS}: \mathrm{Cu}$. Under larger than bandgap excitation $(200 \mathrm{~nm})$, the carrier dynamics involves band to band excitation, trapping at sulphur vacancy, recombination at valence band (420 $\mathrm{nm}$ emission) or $\mathrm{Cu}$ acceptor level (525 $\mathrm{nm}$ emission) and also conduction band to zinc vacancy acceptor centre $(480 \mathrm{~nm}$ emission). As the decay time for DAP recombination is expected to be more and relative concentration of the longer decay component is more than $70 \%$ in $\mathrm{ZnS}: \mathrm{Cu}$, it may be inferred that faster decay component $(0 \cdot 69-0.93 \mu \mathrm{s})$ is contributing to $420 \mathrm{~nm}$ emission and $11 \mu \mathrm{s}$ component is responsible for $525 \mathrm{~nm}$ emission. As the emission peaks are very closely spaced, more than one recombination is reflected in these decay times. Rare earth Eu dopant has been observed to decay in $\mu$ s time scale in different host crystals (Cho et al 2000) and our results also conform to 
this. The $430 \mathrm{~nm}$ and $480 \mathrm{~nm}$ emissions are related to $\mathrm{ZnS}$ host lattice and showed biexponential decay. Whereas the

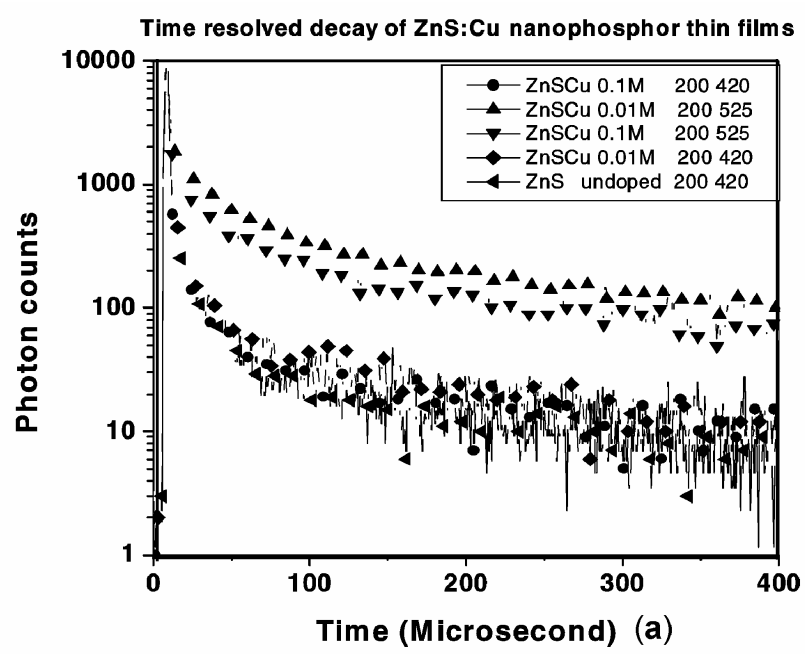

Time Resolved Decay of ZnS:Mn nanophosphor

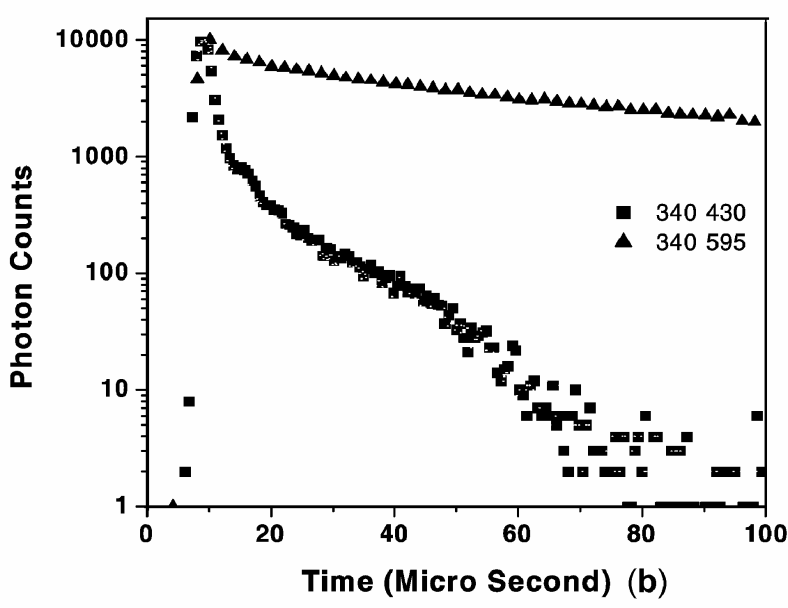

Time resolved decay of ZnS: Eu nanophosphor

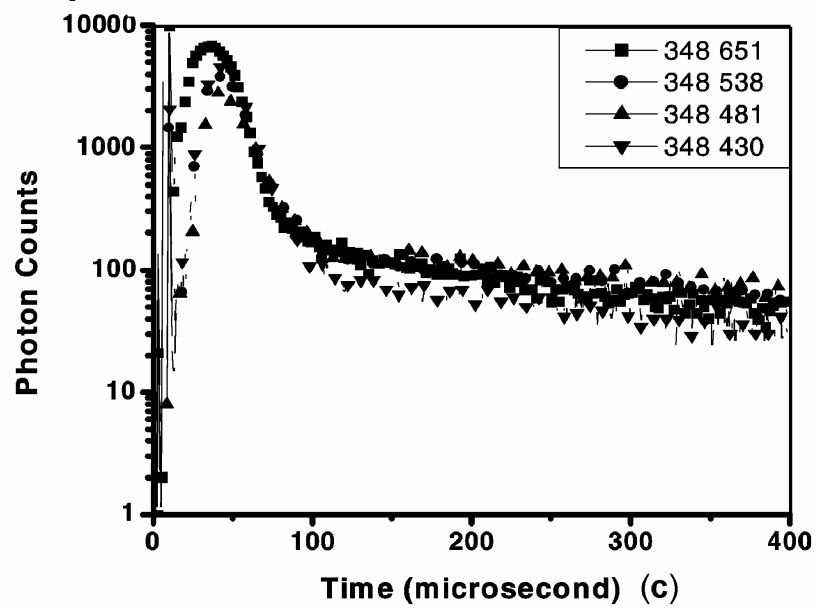

Figure 6. Time resolved decay of PL for (a) undoped $\mathrm{ZnS}$ and $\mathrm{ZnS}: \mathrm{Cu}$, (b) $\mathrm{ZnS}: \mathrm{Mn}$ and (c) $\mathrm{ZnS}:$ Eu nanophosphors. The inset indicates the excitation and emission wavelengths at which time resolved decay measurements were done.
$538 \mathrm{~nm}$ and $651 \mathrm{~nm}$ emission related to Eu ion give single decay time indicating isolation of the recombination process between Eu levels (table 4). Decay parameters of undoped $\mathrm{ZnS}$ bulk phosphor was measured and listed in table 5.

The decay curves for $\mathrm{ZnMgO}$ nanophosphor powders are shown in figure 4 . The curve clearly shows that the decay becomes much slower for the nanophosphor samples with $40 \mathrm{~mole} \% \mathrm{Mg}$ ratio compared to $20 \mathrm{~mole} \% \mathrm{Mg}$ ratio. The decay curves could be fitted into exponential decay equations. The decay times for $20 \mathrm{~mole} \% \mathrm{Mg}$ ratio was 3 and $17 \mu$ s whereas 40 mole $\% \mathrm{Mg}$ ratio nanophosphor showed a much longer decay time of $276 \mu \mathrm{s}$. The long decay times suggested that the luminescence may be produced due to donor-acceptor pair recombination.

For time resolved decay measurement of $\mathrm{PL}$ of $\mathrm{ZnMgO}$ nanocrystalline thin films (figure 5), the samples were excited at $350 \mathrm{~nm}$ with a nanosecond flash lamp and time resolved PL decay was recorded at $435 \mathrm{~nm}$ emission wavelength. Pure undoped $\mathrm{ZnO}$ and $\mathrm{ZnMgO}$ with $100: 10$ $\mathrm{Zn}: \mathrm{Mg}$ ratio only exhibited decay in the nanosecond time scale. Other compositions do not show any decay in nanosecond timescale. Time resolved decay of $\mathrm{ZnO}$ and $\mathrm{ZnMgO}$ (100:25 Zn: Mg ratio) nanophosphor thin films measured with a Xe $\mu$ s flash lamp is shown in figure $5 \mathrm{~b}$.

For time resolved decay measurements as shown in figure $5 \mathrm{a}$, the life times were obtained from exponential reconvolution fit. Decay time obtained for $\mathrm{ZnO}$ was $0.56 \mathrm{~ns}(70 \%), 5.02 \mathrm{~ns}(14 \%)$ and $62.78 \mathrm{~ns}(16 \%)$. Similar decay times were also observed for $\mathrm{ZnO}$ nanocrystalline thin films of $20 \mathrm{~nm}$ particle size (Bauer et al 2004). From the measured life times it may be inferred that the recombination process is multiexponential.

All the nanophosphor thin films exhibit time resolved decay when excited with a $\mu$ s pulse (figure $5 \mathrm{~b}$ ). Pure $\mathrm{ZnO}$ film showed fast decay with a lifetime of $6.47 \mu \mathrm{s}$. The other decay curve exhibited an initial growth and then decay, which could be fitted into a biexponential with lifetimes ranging from 5-8 $\mu$ s and $20-70 \mu \mathrm{s}$ with different contribution ratios with varying $\mathrm{Mg}$ content. Both the lifetime components, however, contribute equally in $\mathrm{ZnMgO}$ films with $\mathrm{Zn}: \mathrm{Mg}$ ratio $100: 25$. Such long lifetimes are usually attributed to donor-acceptor pair (DAP) recombination. As the samples are zinc rich, $\mathrm{Zn}_{i}$ may act

Table 4. Decay parameters of PL peaks of $\mathrm{ZnS}$ :Eu nanophosphor

\begin{tabular}{lcccc}
\hline $\begin{array}{l}\text { Emission } \\
\text { peak }(\mathrm{nm})\end{array}$ & $\tau_{1}(\mu \mathrm{s})$ & Relative $(\%)$ & $\tau_{2}(\mu \mathrm{s})$ & Relative (\%) \\
\hline 430 & $7 \cdot 37$ & 62 & $20 \cdot 77$ & 38 \\
481 & 6.37 & 25 & $16 \cdot 81$ & 75 \\
538 & 9.69 & 100 & & \\
651 & 8.99 & 100 & & \\
\hline
\end{tabular}


Table 5. Decay parameters of PL peak of undoped $\mathrm{ZnS}$ bulk phosphor.

\begin{tabular}{lcccccc}
\hline Emission peak $(\mathrm{nm})$ & $\tau_{1}(\mu \mathrm{s})$ & Relative $(\%)$ & $\tau_{2}(\mu \mathrm{s})$ & Relative $(\%)$ & $\tau_{3}(\mu \mathrm{s})$ & Relative $(\%)$ \\
\hline 430 & 2.49 & 18 & 6.18 & 44 & 17.75 & 38 \\
\hline
\end{tabular}

as a shallow donor and radiative recombination may occur between donor level to deep acceptor levels.

\section{Conclusions}

ZnS nanophosphors doped with transition metal and lanthanide atoms were prepared successfully by wet chemical method. ZnS nanophosphors could be tuned to emit any colour from purple/blue to green $(\mathrm{ZnS}: \mathrm{Cu})$, orange $(\mathrm{ZnS}: \mathrm{Mn})$ and red $(\mathrm{ZnS}: \mathrm{Eu})$ by choosing the proper dopant. Time resolved decay showed faster decay times for purple/blue emission (SA) and microsecond level decay time for impurity emission and shed light on possible carrier dynamics of the recombination process.

Study of steady state PL of $\mathrm{ZnMgO}$ nanophosphor thin films with varying $\mathrm{Mg}$ ratio show that the luminescence in the visible region (blue) enhances significantly with changing $\mathrm{Zn}$ : $\mathrm{Mg}$ ratio, reaching a maximum for $100: 25$ ratio. Time resolved decay measurement shows carrier dynamics with charge trapping in a time scale of hundreds of picosecond. All of the nanophosphor thin films also show luminescence arising from DAP recombination happening in microsecond timescale.

The study of optical properties of $\mathrm{ZnMgO}$ nanocomposites in the nanocrystalline form shows very clearly that it is possible to obtain enhanced luminescence properties in the visible region by changing the ratio of $\mathrm{Mg}$ content. The enhancement of luminescence of $\mathrm{ZnMgO}$ (40 mole\% $\mathrm{Mg}$ ) is about 62 times compared to pure $\mathrm{ZnO}$ prepared by the same synthesis method. The enhancement of luminescence is also associated with a slow decay component, which could be due to deep traps created in the high $\mathrm{Mg}$ ratio nanocomposites. Such nanocomposites hence could be very good nanophosphors for various display purposes.

\section{References}

Bauer C, Boschloo G, Mukhtar E and Hagfeldt A 2004 Chem. Phys. Lett. 387176

Bhargava R N, Gallagher D, Hong X and Nurmikko A 1994 Phys. Rev. Lett. 72416

Bol A A and Meijerink A 1998 Phys. Rev. B58 R15 997

Chander H 2005 Mater. Sci. \& Eng. R49 113

Chander Harish, Chawla Santa, Jayanthi K and Kar M 2006 Proc. Indo-Japan workshop on $\mathrm{ZnO}$ materials and devices (ed.) R M Mehra et al (Pentagon Press) pp 9-11

Chawla Santa, Jayanthi K and Chander Harish 2006 Proc. IndoJapan workshop on $\mathrm{ZnO}$ materials and devices (ed.) R M Mehra et al (Pentagon Press) pp 12-14

Cho A et al 2000 J. Lumin. 91215

Jin Y et al 2001 Solid State Commun. 119409

Karar N, Singh F and Mehta B R 2004 J. Appl. Phys. 95656

Kim J W, Kang H S, Kim J H and Lee S Y 2006 J. Appl. Phys. 100033701

Lee S et al 2004 Mater. Lett. 58342

Matsuhara K et al 2003 Mater. Res. Soc. Symp. Proc. 763 B7.2.1

Ogawa Y and Fujihara S 2005 Phys. Status Solidi (a) 2021825

Peng W Q, Cong G W, Qu S C and Wang Z G 2006 Opt. Mater. 29313 